\title{
Proceso de atención enfermero a persona con insuficiencia renal crónica
}

\author{
Sarely Trujano Trujano,* Sara Santiago García**
}

\begin{abstract}
RESUMEN
El proceso de atención en enfermería (PAE) tiene como finalidad brindar atención integral y especializada a cada agente de cuidado, impulsando y conservando la salud del usuario cuando lo requiera. Este PAE se realizó en el Hospital "Lic. Adolfo López Mateos" y se utilizó la teoría del déficit de autocuidado de Dorothea Orem. Se trata de Jesús (nombre ficticio), masculino de 66 años con un padecimiento de insuficiencia renal crónica y peritonitis bacteriana; HAS (hipertensión arterial sistémica), DM T2 (diabetes mellitus tipo 2) descontroladas debido a una falta de adhesión al plan terapéutico.
\end{abstract}

Palabras clave: Proceso de atención enfermero, Teoría Dorothea Orem.

\section{Nursing process person with chronic renal failure}

\begin{abstract}
The completion of the Nursing Care Process is designed to provide comprehensive care to each agent specialized care by developing and maintaining the health of the user when required. The Nursing Care Process (SAP) at the Hospital "Lic. Adolfo López Mateos", was applied using Dorothea Orem's theory in conjunction with his theory of self-care deficit. This is Jesus, 66 years old male with chronic renal disease, bacterial peritonitis, HAS (hypertension), T2 DM (diabetes mellitus type 2) uncontrolled due to a lack of adherence to therapeutic plan.
\end{abstract}

Key words: Nursing process, Dorothea Orem Theory.

\section{INTRODUCCIÓN}

$\mathrm{H}$ oy en día, la enfermería ha suscitado un interés tal entre los profesionales que los ha llevado a demostrar, mediante argumentos de corte científico, su consolidación como una ciencia joven. Algunas de las principales preocupaciones de esta ciencia son la promoción, la prevención y la recuperación del estado de salud del agente de cuidado, así como la disminución de riesgos por medio de la educación para la salud.
El PAE tiene como objetivo la interacción entre la teoría y la práctica clínica; es un método sistemático, racional y flexible de aplicación en la práctica clínica que nos permite brindar cuidados integrales para satisfacer, mejorar e implementar hábitos en la salud acorde a las respuestas humanas.

Los conocimientos del PAE son considerados fundamentales en la práctica y la teoría profesional de enfermería mostrando del conocimiento en la práctica cotidiana, permitiendo su aplicación, ejecución y evaluación basada en una fundamentación científica.

*Alumna del 8vo semestre de Licenciatura en Enfermería, FES Zaragoza.

** Asesora Metodológica, Profesora Académica de la Licenciatura en Enfermería de FES Zaragoza.

Correspondencia: Sarely Trujano Trujano. Universidad Nacional de México UNAM. Facultad de Estudios Superiores Zaragoza Lic. Enfermeria. E-mail: sare12_rorriz@hotmail.com

Este artículo puede ser consultado en versión completa en http://www.medigraphic.com/enfermerianeurologica 
Ofrecer un cuidado integral fundado en la comunicación y la empatía entre el enfermero y el agente de cuidado, permitirá que el profesional desarrolle habilidades, conocimientos y experiencia para identificar alteraciones del proceso salud-enfermedad.

\section{PRESENTACIÓN DEL CASO}

Este PAE está dirigido a un agente de cuidado que llamaremos Jesús (nombre ficticio); paciente masculino de 64 años. Jesús arribó al Servicio de Urgencias de Adultos con diagnóstico médico de peritonitis bacteriana, insuficiencia renal crónica, hipertensión arterial, diabetes mellitus tipo II descontroladas, con signos vitales de $37.5^{\circ} \mathrm{C}$, frecuencia respiratoria 20 x', frecuencia cardiaca 69 x’ y tensión arterial 162/86 mmHg. Se le planteó la posibilidad de elaborar su caso clínico con fines académicos (paciente con enfermedades crónicas degenerativas descontroladas), se le explicó que éste le permitirá participar en su propio cuidado y se le ofreció atención individualizada. Se requirió de la autorización a través de un consentimiento informado reiterando que la información se usará para fines académicos.

Los datos contribuyeron para la realización del diagnóstico de enfermería real y de riesgo, se inició la jerarquización priorizando las necesidades, utilizando como herramienta principal la Teoría de Dorothea Orem. La etapa de planeación tuvo como finalidad llevar a cabo intervenciones de enfermería de manera integral y especializada. Se ejecutaron las intervenciones de enfermería de forma racional, lógica y sistemática. Posteriormente se evaluaron de manera individualizada para determinar el impacto de las intervenciones de enfermería, reconociendo la evolución o disminución de los problemas en su nivel óptimo de salud.

\section{INSUFICIENCIA RENAL CRÓNICA}

La insuficiencia renal crónica (IRC) se define como disminución grave de la masa de nefronas en un lapso duradero que culmina en uremia.

Cuando existe un funcionamiento renal de $100-80 \%$, no existe sintomatología; sin embargo, hay que valorar la administración de antiinflamatorios no esteroideos. Cuando es de 50-20\%, existe aumento de creatinina sérica de 1.8-14.4 $\mathrm{mg} / \mathrm{dL}$ y los síntomas aparentes son nicturia y malestar leve; sin embargo, cuando se ha llegado a una función renal de $<10 \%$, los síntomas son los siguientes: Cansancio, letargo, náuseas, anorexia y pigmentación pardusca. ${ }^{1}$

\section{Peritonitis}

La peritonitis es una de las principales complicaciones de los pacientes con diálisis peritoneal automatizada (DPA). La infección tiene un gran impacto en el pronóstico a largo plazo, disminuyendo el tiempo de vida útil de la membrana peritoneal. En todo paciente con diálisis que presenta líquido peritoneal turbio se debe sospechar que presenta peritonitis (Evidencia). ${ }^{1}$

\section{Hipertensión arterial sistémica}

La prevalencia de HAS en México es de $30.7 \%$ en adultos mayores de 20 años, y sólo el $14.6 \%$ logran su control tensional. ${ }^{3} \mathrm{La}$ hipertensión, según el reporte de la OMS, aumenta el riesgo cardiovascular cuando hay daño a un órgano blanco, y la presencia de este órgano dañado va a influir en el método y el tratamiento.

\section{Diabetes mellitus tipo dos (T2)}

El término diabetes proviene de la expresión griega "fluir a través de" (como sería orinar excesivamente) y mellitus significa "similar a la miel".

Tipo 2 se conoce al adulto insulinodependiente. Es ocasionada por resistencia a la acción de la insulina y por falla de las células B. Estos dos trastornos suceden simultáneamente y manifiestan de manera variable en cada persona que la padece.

\section{Requisitos de desviación de la salud}

Se trata de Jesús, masculino de 66 años, con escolaridad de preparatoria, pensionado. Con antecedentes heredofamiliares: Padre finado por insuficiencia renal crónica y madre sin antecedentes de enfermedades crónicas-degenerativas, antecedentes personales no patológicos, originario del estado de Oaxaca y residente del D.F., casado, creyente, habita en casa propia en compañía de su esposa, cuenta con todos los servicios intra y extradomiciliarios, toxicomanías negadas. Antecedentes personales patológicos alérgicos negados, quirúrgicos [protectomía abierta, colocación de catéter Tenckhoff en región abdominal, diabetes mellitus con antigüedad de 25 años, en tratamiento con actual con glargina (insulina de acción prolongada)] 5 UI por la mañana. HAS diagnosticada desde hace 8 años, tratamiento actual con amlodipino una tableta vía oral por la noche. Insuficiencia renal crónica, desde hace dos años; inició el tratamiento hace un año tres meses actualmente, tratada con diálisis peritoneal automatizada a través de la maquina cicladora (home choice); eritropoyetina tres ámpulas, tres veces por semana, calcitrol una tableta $\mathrm{VO}$ cada 24 horas, ácido fólico una tableta VO cada 24 horas, fumarato ferroso una tableta $\mathrm{VO}$ cada 24 horas.

\section{DISCUSIÓN}

Los estudiantes de la Licenciatura de Enfermería desarrollaron algunas habilidades durante el proceso de atención 
Cuadro I. Plan estandarizado

Requisito alterado: Prevención de peligros para la vida, funcionamiento humano y bienestar Indicios: El día 27/10/10 leucocitosis (11.2), neutrófilos (9.55), linfocitos (9.70), líquido dializante a su egreso turbio, febrícula durante el turno vespertino

\section{Código: 00004}

Diagnóstico: Infección (peritonitis) r/c enfermedad crónica (insuficiencia renal crónica), alteración de las defensas primarias (rotura de la piel), por instalación de catéter Tenckhoff $\mathrm{m} / \mathrm{p}$ temperatura por encima y por debajo de los límites

$\begin{array}{ll}\text { Dominio: } & \text { Clase: } 2 \\ 11 & \text { Lesión física } \\ \text { Seguridad } & \\ \text { y protección } & \end{array}$

Resultados esperados NOC: Limitar la infección evitando que se propague a otros órganos

\begin{tabular}{ll}
\hline Indicadores & Puntuación Diana \\
\hline
\end{tabular}

070307 fiebre

070333 dolor

070326 aumento de leucocitos

\begin{tabular}{|c|c|c|c|}
\hline 3 & 1 & 2 & 3 \\
\hline 3 & 1 & 2 & 3 \\
\hline 2 & 1 & 2 & 3 \\
\hline
\end{tabular}

\begin{tabular}{lcc}
\hline & Intervenciones NIC: & Sistema de enfermería: TC \\
\hline Código & Intervenciones & Fundamentación científica \\
\hline
\end{tabular}

3660 Protección contra las infecciones

- Observar los signos y síntomas de infección sistémica y localizada.

- Observar el grado de vulnerabilidad del paciente a las infecciones

- Vigilar el recuento de glóbulos blancos y los resultados diferenciados Mantener las normas de asepsia para el paciente de riesgo

- Inspeccionar la existencia de enrojecimiento, calor externo o drenaje en la piel y las membranas mucosas

- Inspeccionar el estado de cualquier incisión/herida quirúrgica

- Lavarse las manos antes y después de cada actividad de cuidados de paciente

- Llevar en práctica precauciones universales

- Garantizar una manipulación aséptica de todas las líneas IV y el catéter Tenckhoff

Cuando los gérmenes logran traspasar las primeras barreras defensivas de organismo (piel y mucosas) y se alojan en tejidos considerados normalmente como estériles, tiene lugar la infección.

Dependiendo de la virulencia del inóculo, así como de la inmunocompetencia del paciente, las defensas inmunológicas locales pueden ser superadas, produciéndose entonces la irrupción de los gérmenes al torrente circulatorio y el establecimiento de una bacteremia.

Las defensas del hospedero contra la infección son de tres órdenes:

1. Las barreras mecánicas

2. Las defensas celulares

3. Las defensas humorales

\begin{tabular}{ll}
\hline Evaluación & Evaluación de todo el plan de cuidado \\
\hline
\end{tabular}

La infección se mantuvo, no aumentó pero tampoco disminuyó debido a que llevaba un día con antibiótico.

Siguiendo con su esquema de antibiótico.

Al final del turno se observó parte del catéter Tenckhoff, limpio y sin datos aparentes de infección.

El líquido dializante durante el turno siguió turbio.

Puntuación diana: 1. Gravemente comprometido; 2. Sustancialmente comprometido; 3. Moderadamente comprometido; 4. Levemente comprometido, y 5. No comprometido. De acuerdo a la teoría de sistemas de D. Orem, el agente de cuidado está en estado compensatorio totalmente (TC).

de enfermería: investigación, búsqueda de bibliografía actualizada y válida. También desarrollaron conocimientos acerca de la metodología del enfermero, enriquecidos con distintos puntos de vista del padecimiento del agente de cuidado (Cuadro I).

Posteriormente, en la evaluación del plan estandarizado sobre el agente de cuidado, no se pudo valorar totalmente debido a la corta estancia en el Servicio de Urgencias. Después fue hospitalizado en medicina interna para ser valorado por médicos especialistas en nefrología y así poder descartar patologías secundarias; sin embargo, durante ese tiempo se trató de mantener el estado de salud actual.
Concorde a los objetivos esperados, se logra limitar las infecciones en el paciente y se mantiene estable.

Las intervenciones fueron las idóneas.



Por otro lado, nuestra opinión coincide con el Instituto de Salud del Estado de México: la población geriátrica es susceptible de padecer enfermedades crónico-degenerativas y sus correspondientes complicaciones, por tal motivo es necesario que la población brinde la importancia necesaria al cuidado de su salud, sobre todo si tienen antecedentes heredofamiliares. ${ }^{16}$

\section{BIBLIOGRAFÍA}

1. Murtagh J. Práctica general de medicina. 3ra ed. México: McGraw-Hill Interamericana; 2007.

2. Barrera P, Zambrano P, Contreras A, Dreves P. Complicaciones infecciosas en diálisis peritoneal crónica Rama Nefrología Pediátrica - Sociedad Chilena de Pediatría. Rev Chil Pediatr 2008; 79 (5): 522-536.

3. Alfaro-LeFevre R. Aplicación del proceso enfermero "fomentar el cuidado en colaboración”. 5ta ed. Editorial Manson; 2005. 
Enf Neurol (Mex)

4. Taylor SG, Orem DE. Teoría del déficit de autocuidado. En: Marriner A, Raile M. Modelos y teoría en enfermería. 6ta ed. España: Elsevier; 2007: 267-295.

5. Lépor ILR. Farmacología clínica de bolsillo. Buenos Aires: Editorial Laboratorios Schering-Plough; 2003.

6. NANDA Internacional Diagnósticos enfermeros: definiciones y clasificación. 2005-2006, Elsevier.
7. NANDA Internacional Diagnósticos enfermeros: definiciones y clasificación. 2009-2011, Elsevier.

8. Dochterman MJ, Bulechek G. Clasificación de intervenciones de enfermería (NIC). 4ta ed. España: Mosby \& Elsevier; 2005.

9. Dochterman MJ, Bulechek G. Clasificación de intervenciones de enfermería (NIC). 4ta ed. España: Mosby \& Elsevier; 2005.

10. http://salud.edomexico.gob.mx/html/article.php?sid=27. 